\title{
Mechanisms responsible for antibody-dependent, cell-mediated cytotoxicity to isolated hepatocytes in chronic active hepatitis
}

\author{
C. GONZALES, A. M. G. COChRANE, A. L. W. F. EDDLESTON, AND ROGER \\ WILLIAMS
}

From the Liver Unit, King's College Hospital and Medical School, Denmark Hill, London

SUMMARY Lymphocytes from patients with chronic active hepatitis have been found to be cytotoxic for isolated rabbit hepatocytes. Although this reaction has been shown to be of the antibodydependent type, no autologous serum was added to the assay system and in the present experiments the source of the antibody has been sought. The failure of puromycin to block the reaction argued against a role for antibody synthesised during the culture period, and the demonstration that normal mononuclear cells could become cytotoxic when preincubated in chronic active hepatitis sera was more in favour of the passive acquisition of an antibody from the circulation. Evidence for the existence of free antibody in the sera reacting with hepatocyte surface antigens came from an additional series of experiments in which it was shown that preincubation of hepatocytes in chronic active hepatitis sera rendered them susceptible to damage by normal mononuclear cells. This effect was almost completely abolished by adding a membrane lipoprotein fraction of human liver (LSP) to the sera during the preincubation step, suggesting that the LSP contained those antigens on the hepatocyte surface against which the majority of the antibodies were directed.

Lymphocytes from patients with chronic active hepatitis have been shown to be cytotoxic for autologous liver cells (Wands et al., 1975; Geubel et al., 1976), Chang cells (Wands et al., 1975; Jacques et al., 1976), and rabbit hepatocytes (Thomson et al., 1974).

In the latter system the reaction could be blocked by the addition of liver specific membrane lipoprotein fraction (LSP) suggesting that this contained the major target antigens involved in the in vitro reaction (Thomson et al., 1974). By preparing lymphocyte subpopulations it was possible to show that the cytotoxic lymphocytes were not $T$ cells, but carried complement receptors. This, together with the observation that the reaction could be blocked by aggregated immunoglobulin, would be consistent with the operation of an antibody-dependent cytotoxic mechanism, possibly $\mathrm{K}$ cell mediated (Cochrane et al., 1976). Since autologous serum had not been added to the system the source of the antibody was unknown. In the present study we describe additional experiments in which it has been shown that the antibody can be carried into the

Received for publication 15 November 1978 assay system on the surface of normal lymphocytes. In addition, the serum of patients with chronic active hepatitis has been examined for an antibody which will render hepatocytes susceptible to a damaging attack by normal mononuclear cells.

\section{Methods}

Sera were obtained from 18 patients with chronic active hepatitis. In all instances the diagnosis had been confirmed histologically. As a control group sera were obtained from 18 preoperative surgical patients with no evidence of liver disease. The sera were stored at $-20^{\circ} \mathrm{C}$ until required for use.

Three patients were untreated at the time the serum was collected, the remainder receiving prednisone $(10-15 \mathrm{mg}$ daily) either alone or with azathioprine $(75 \mathrm{mg}$ daily). The ability of the sera to induce cytotoxicity was not related to the type or dose of immunosuppressive therapy.

\section{MICROCYTOTOXICITY ASSAY}

The assay was carried out using hepatocytes prepared by enzyme digestion of livers from freshly killed rabbits and maintained in tissue culture flasks for 
up to three weeks, as described in detail elsewhere (Cochrane et al., 1977). The morphological appearance of the cells, both on light and electron microscopy and their ability to synthesise albumin suggested that they were viable hepatocytes (Hughes et al., 1976).

Lymphocytes were prepared from peripheral venous blood by dextran sedimentation, filtration through a cotton wool column (Rocklin et al., 1970), followed by centrifugation over Ficoll triosil (Böyum, 1968). Lymphocytes were added to hepatocytes in a ratio of 400 to 1 in microtest plates and incubated for 48 hours at $37^{\circ} \mathrm{C}$ in a $5 \% \mathrm{CO}_{2}$ atmosphere. Detached hepatocytes and lymphocytes were then gently washed clear and the percentage cytotoxicity calculated from the formula:

average number cells in control wells average number in test wells

average number in control wells

The upper limit of the normal range for cytotoxicity $(32 \%)$ has been taken as two standard deviations above the mean value $(2.9 \%)$ obtained in 35 normal controls.

Techniques for induction of cytotoxicity

In the first series of experiments, lymphocytes from one normal control subject were purified as above and divided into aliquots each containing $1 \times 10^{6}$ cells. Each aliquot was then incubated at $37^{\circ} \mathrm{C}$ for 30 minutes with either $500 \mu \mathrm{l}$ of control or chronic active hepatitis serum. After centrifugation at $200 \mathrm{~g}$ for five minutes, the serum was removed and lymphocytes washed twice in RPMI 1640. The cytotoxicity of these lymphocytes for hepatocytes was then compared with that obtained when lymphocytes from the same donor were preincubated with foetal calf serum.

In the second series of experiments hepatocytes were seeded into microtest plates at a density of approximately 200 cells/well and incubated for 24 hours to allow viable cells to adhere. After aspiration of tissue culture medium $10 \mu$ l foetal calf serum, control serum, or chronic active hepatitis serum were added to at least 10 wells and the plates incubated for 30 minutes at $37^{\circ} \mathrm{C}$. The serum was then aspirated using a $1 \mathrm{ml}$ syringe and 25 gauge needle and $10 \mathrm{ml}$ of tissue culture medium added. Wells were again aspirated, then normal lymphocytes added at a ratio of $\mathbf{4 0 0}$ to each hepatocyte. Cytotoxicity was calculated in the usual way after 48 hours' incubation at $37^{\circ} \mathrm{C}$. LSP at a concentration of $0.5 \mu \mathrm{g} / 10 \mu \mathrm{l}$, prepared by the method of MacFarlane et al. (1977), was added to one of the rows of 10 wells containing hepatocytes at the same time as serum from the patients with chronic active hepatitis to determine whether this would prevent induced cytotoxicity. After washing, normal lymphocytes were then added and cytotoxicity estimated in the usual way.

The Wilcoxon rank sum test was used to assess the significance of the changes in cytotoxicity induced by the various procedures.

\section{Results}

In order to determine whether antibody synthesised during the assay was responsible for the observed cytotoxicity, protein synthesis was inhibited by the addition of $10 \mu \mathrm{g}$ puromycin to each of 10 wells containing cytotoxic lymphocytes and hepatocytes. In each of five experiments there was no significant reduction in the per cent cytotoxicity, the mean value being $48.4 \pm 1.7 \%$ (SEM) without and $51 \cdot 4 \pm 4.8 \%$ with the puromycin.

\section{Induction of cytotoxicity in normal lymphocytes by preincubation with patient's serum}

Aliquots of normal lymphocytes from one healthy individual were incubated in eight different control sera, in eight different aliquots of one batch of foetal calf serum and in each of the 18 chronic active hepatitis sera. The mean cytotoxicity of those preincubated in control sera $(19.3 \pm 7 \cdot 7 \%$, mean \pm SEM) was not significantly different from that of the same lymphocytes preincubated in foetal calf serum $(19 \cdot 8 \pm 4 \cdot 4 \%)$ (Fig. 1$)$.

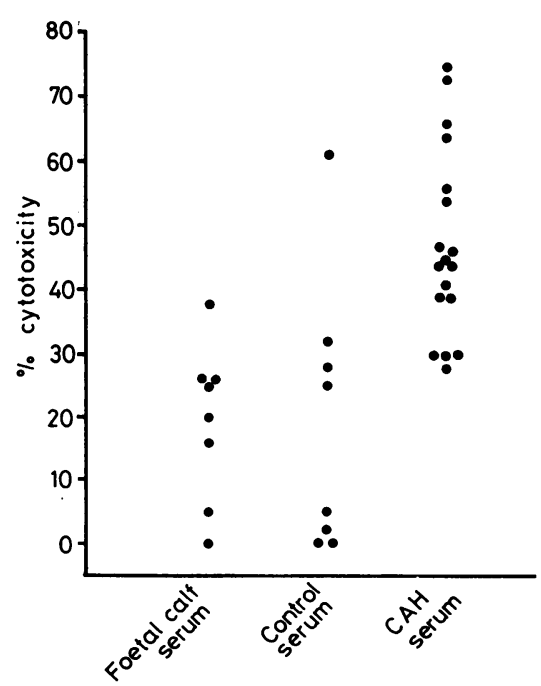

Fig. 1 The effect on hepatocyte cytotoxicity of preincubating lymphocytes from a normal subject with foetal calf serum, control sera or chronic active hepatitis sera. CAH: chronic active hepatitis. 
When serum from patients with chronic active hepatitis was used for the preincubation, the mean cytotoxicity $(47 \cdot 5 \pm 4.7 \%)$ was significantly higher than that obtained with control serum or foetal calf serum $(P<0.01$ and $P<0.01$, respectively).

\section{Induction of cytotoxicity by preincubation of} hepatocytes with serum

The mean cytotoxicity of normal lymphocytes for hepatocytes preincubated with control serum (19.5 $\pm 3.5 \%$ ) was not significantly different from that obtained after preincubation with foetal calf serum $(17 \cdot 4 \pm 3.3 \%$ ) (Fig. 2). However, the cytotoxicity of normal lymphocytes for hepatocytes preincubated in serum from patients with chronic active hepatitis $(52.8 \pm 5.0 \%)$ was significantly higher than that obtained with either control serum or foetal calf serum $(P<0.01$ and $P<0.01$, respectively). Addition of $0.5 \mu \mathrm{g} \mathrm{LSP}$ at the time the rabbit hepatocytes were incubated with the chronic active hepatitis serum significantly reduced the induced cytotoxicity from $52.8 \pm 5.0 \%$ to $22.5 \pm 3.3 \%(\mathrm{P}<0.01)$. This value did not differ significantly from that found after preincubating the hepatocytes with control serum or foetal calf serum.

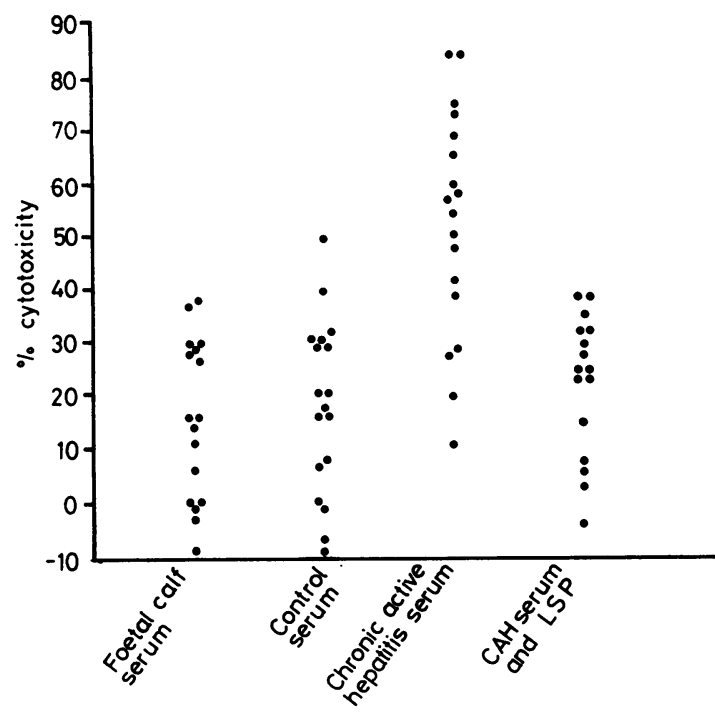

Fig. 2 The change in the susceptibility of hepatocytes for damage by normal mononuclear cells after preincubation of the liver cells in various sera. CAH: chronic active hepatitis.

\section{Discussion}

Evidence from earlier studies strongly suggests that the cytotoxic reaction of lymphocytes from patients with chronic active hepatitis for isolated hepatocytes is of the antibody-dependent, cell-mediated type (Cochrane et al., 1976), although the exact nature of the effector cell-for example, macrophage $K$ cell, etc- has not been determined. No autologous serum is added in this assay, and there are two possible sources for the antibody involved. Its synthesis by B lymphocytes during their incubation with hepatocytes is one possibility but the failure of puromycin, in a concentration known to inhibit protein synthesis (David, 1965), to suppress the cytotoxicity is evidence against in vitro antibody synthesis. A second possibility is that the effector cells carry the antibody into the assay on their surface either as immune complexes or, if macrophages are involved, as cytophilic antibody. The finding in the present study that preincubation of mononuclear cells from normal individuals with serum from chronic active hepatitis confers cytotoxicity is consistent with this hypothesis. However, additional experiments will be needed to determine whether immune complexes or a cytophilic antibody are responsible for the induced cytotoxicity.

The results of the second series of experiments in which hepatocytes preincubated with chronic active hepatitis serum were shown to become susceptible to a damaging attack by normal mononuclear cells are consistent with the presence in the serum of antibodies reacting with determinants on the surface of the hepatocytes. The antibody-coated liver cells would then be damaged by the attachment of $\mathbf{K}$ cells present in the normal lymphocyte population. The very obvious inhibition of this effect by the addition to the serum of as little as $0.5 \mu \mathrm{g} \mathrm{LSP}$ suggests that the LSP contains those antigenic determinants on the hepatocyte surface against which the majority of the antibodies are directed. Indeed, using a sensitive radioimmunoassay (Jensen et al., 1978a), we have directly demonstrated the presence of antibody to LSP in 29 of 30 cases with untreated chronic active hepatitis. The finding of a significant correlation between the titre of this antibody and the degree of periportal liver cell necrosis on the liver biopsies from these patients (Jensen et al., 1978b), together with the present observations showing that the antibody can induce hepatocyte damage by normal mononuclear cells, are further evidence of the potential importance of this antigen/antibody system in the pathogenesis of chronic active hepatitis.

We wish to thank Linda Rimmer for editorial assistance. The work was supported by the Wellcome Trust.

\section{References}

Böyum, A. (1968). Separation of leucocytes from blood and 
bone marrow. Scandinavian Journal of Clinical and Laboratory Investigation, 21, suppl. 97, 9-29.

Cochrane, A. M. G., Moussouros, A., Portmann, B., McFarlane, I. G., Thomson, A. D., Eddleston, A. L. W. F., and Williams, R. (1977). Lymphocyte cytotoxicity for isolated hepatocytes in alcoholic liver disease. Gastroenterology, 72, 918-923.

Cochrane, A. M. G., Thomson, A. D., Moussouros, A., Eddleston, A. L. W. F., and Williams, R. (1976). Antibodydependent cell-mediated ( $K$ cell) cytotoxicity against isolated hepatocytes in chronic active hepatitis. Lancet, 1 , 441-444.

David, J. R. (1965). Suppression of delayed hypersensitivity in vitro by inhibition of protein synthesis. Journal of Experimental Medicine, 122, 1125-1134.

Geubel, A. P., Keller, R. H., Summerskill, W. H. J., Dickson, E. R., Tomasi, T. B., and Shorter, R. G. (1976). Lymphocyte cytotoxicity and inhibition studied with autologous liver cells: observations in chronic active liver disease and the primary biliary cirrhosis syndrome. Gastroenterology, 71, 450-456.

Hughes, R. D., Cochrane, A. M. G., Thomson, A. D., Murray-Lyon, I. M., and Williams, R. (1976). The cytotoxicity of plasma from patients with acute hepatic failure to isolated rabbit hepatocytes. British Journal of Experimental Pathology, 57, 348-353.

Jacques, E., De Villiers, D., Thomas, H. C., and Sherlock, S. (1976). Lymphocyte mediated cytotoxicity for Chang liver cells in acute and chronic liver disease (Abstract). Gut, 17, 389.

Jensen, D. M., McFarlane, I. G., Nicholson, A., Eddleston, A. L. W. F., and Williams, R. (1978a). The development of a radioimmunoassay for the detection of antibodies to a liver-specific membrane lipoprotein (LSP). Journal of Clinical and Laboratory Immunology, 1 . (In press).

Jensen, D. M., McFarlane, I. G., Portmann, B. S., Eddleston, A. L. W. F., and Williams, R. (1978b). The detection of antibodies directed against a liver-specific membrane lipoprotein in patients with acute and chronic active hepatitis. New England Journal of Medicine, 299, 1-7.

McFarlane, I. G., Wojcicka, B., Zucker, G. M., Eddleston, A. L. W. F., and Williams, R. (1977). Purification and characterisation of human liver-specific membrane lipoprotein (LSP). Clinical and Experimental Immunology, 27. 381-390.

Rocklin, R. E., Meyers, O. L., and David, J. R. (1970). An in vitro assay for cellular hypersensitivity in man. Journal of Immunology, 104, 95-102.

Thomson, A. D., Cochrane, M. A. G., McFarlane, I. G., Eddleston, A. L. W. F., and Williams, R. (1974). Lymphocyte cytotoxicity to isolated hepatocytes in chronic active hepatitis. Nature, 252, 721-722.

Wands, J. R., Perrotto, J. L., Alpert, E., and Isselbacher, K. H. (1975). Cell-mediated immunity in acute and chronic hepatitis. Journal of Clinical Investigation, 55, 921-929. 